\title{
A new exact equivalent circuit of the medium voltage three-phase induction motor
}

\author{
Laura Collazo Solar', Angel A. Costa Montiel², Miriam Vilaragut Llanes ${ }^{3}$, \\ Vladimir Sousa Santos ${ }^{4}$, Abel Curbelo Colina ${ }^{5}$ \\ 1,2,3,5 Universidad Tecnológica de la Habana "José Antonio Echeverría", Cuba \\ ${ }^{4}$ Energy Department, Universidad de la Costa, Colombia
}

\begin{tabular}{l} 
Article Info \\
\hline Article history: \\
Received Apr 6, 2020 \\
Revised May 28, 2020 \\
Accepted Jun 6, 2020 \\
\hline
\end{tabular}

\section{Keywords:}

Equivalent circuit

Induction motor

Motor parameters

Power balance

Rotor circuit

\begin{abstract}
This paper proposes a new equivalent circuit for medium voltage and great power induction motors considering the more complete information given by the manufacturer. A methodology for obtaining the parameters of the equivalent circuit is presented, having this circuit the advantage of allowing the electrical calculation of all the power losses and the realization of the power balance. It is an achievement of this work a new way of calculating and representing the additional losses using a resistance located in the rotor circuit. Then, three types of losses are considered as a part of a power balance: the conventional or joule effect variable losses, the constant losses, and the additional losses. The proposed method is straight and non-iterative. It was applied to a case study motor of $6000 \mathrm{~V}$ and $2500 \mathrm{~kW}$ located at the Maximo Gomez Power Plant in Cuba.
\end{abstract}

Copyright $@ 2020$ Institute of Advanced Engineering and Science. All rights reserved.

\section{Corresponding Author:}

Vladimir Sousa Santos,

Energy Department,

Universidad de la Costa,

Calle 58 No.55-66, Barranquilla, Colombia.

Email: vsousa1@cuc.edu.co

\section{INTRODUCTION}

The three-phase induction motor is the electromechanical converter of the electric drive of the great majority of mechanisms or mechanical loads and the principal electrical energy consumption of industrial installations [1, 2]. This means that the knowledge of the mathematical models that allow the prediction of the behavior of these motors on the electric grid as well as on the mechanical system of which is its driver has great importance. The model in the steady-state used almost universally is shown in Figure 1 [3].

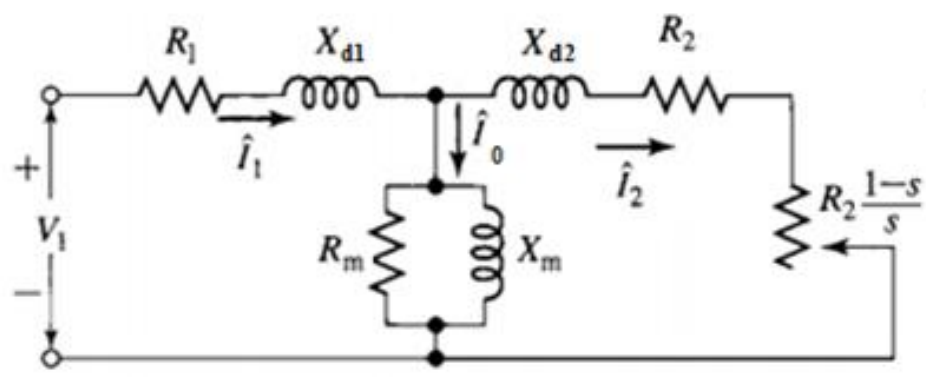

Figure 1. Classic exact equivalent circuit of the induction motor 
In this per phase model of the motor $R_{1}$ is the stator's resistance, $X_{d 1}$ is the leakage reactance, $\mathrm{R}_{2}$ the rotor resistance, $\mathrm{X}_{\mathrm{d} 2}$ the leakage reactance of the rotor, $\mathrm{R}_{\mathrm{m}}$ the core losses resistance, $\mathrm{X}_{\mathrm{m}}$ the magnetizing reactance, $\mathrm{V}_{1}$ the per phase voltage of the stator, $\mathrm{I}_{1}, \mathrm{I}_{2}$, and $\mathrm{I}_{0}$ the stator, rotor, and no-load currents respectively. In this circuit in the resistance $R_{2}(1-s) / s$ is where all the power transformed into mechanical form, including the mechanical and additional losses, is dissipated.

It must be pointed out that this circuit can only be used to obtain the behavior in a steady-state under stable operation conditions because the parameters used correspond to this condition. Its principal application is the realization of an energy efficiency analysis under different operating conditions $[4,5]$ and as an initial step to develop the motor models for power flow studies. To use this circuit, it is necessary to properly identify its parameters. For this, the following general procedures are known:

- Through the constructive characteristics of the machine and using different magnetic field calculation methods like the finite element method $[6,7]$

- Through no-load tests [8-10].

- Through frequency response methods and the identification of transient response [11].

- Through the datasheet supplied by the manufacturer [5, 12-14].

In some cases, constructive information is not available because the manufacturers don't offer it that easily or the equipment for the realization of the test, and the method for identification is also not available, or even the motor is not available because it hasn't been bought. In these cases, if great accuracy is not required (a maximum error around 15\%) is possible to use the fourth method, which is very simple and is based on the knowledge of the datasheet of the motor and an estimation of the losses. This general method is the one chosen. Right ahead, the existing principal works in the scientific literature based on the selection of this method are commented on.

One of the first works reported in the scientific literature was by Natarajan and Misra [15]. It uses the information for three different load states but makes some simplifications relative to the consideration of the magnetizing branch and lessens the voltage drop on the stator as well as the saturation and the skin effect. The proposal that appears in [16] for the relation between the leakage reactance of the stator and one of the rotors is adopted.

Almost simultaneously with this work, another one made by Ansuj, Shokoo, and Schinziger [17] was presented. In this later work, a methodology based on a sensitivity analysis was exposed but has the difficulty of needing the equations that interrelate the behavioral characteristics and parameters of the motor. The identification method of maximum likelihood and the minimum variance criteria are used to obtain the parameters.

Some years later, Haque [18] presented an iterative proceeding based on the solution of an equation system deduced from the equivalent circuit. The magnetizing reactance was calculated from a reactive power balance on the motor. It neglects the additional losses and considers constant mechanical losses. The division between the stator and rotor leakage reactance is made similarly as Natarajan and Misra [15] did.

Motivated by the necessity of making a model of the induction motor in the electromagnetic transients program (EMTP) for stationary as well as a transient state, a model with its corresponding parameters was presented, taking under consideration the variation of the parameters of the rotor for double cage and deep bars motors. This line was developed by Joaquim Pedrá from the "Universidad Politécnica de Catalunya" [19-21]. This same problem, the necessity of considering the parameters variation for transient analysis, is observed in [22] considering the same conventional equivalent circuit, but making the rotor parameters a function of the slip. In [23] Pedrá and his working group expose the way on which the saturation on the reactance of the machine is considered and in [24] the variation of the mechanical and additional losses about the variation of the speed and current are taken into consideration.

One of the more recent and complete works on this issue was carried by a group of researchers from the "Universidad Federal de Itajuba", in Brazil, and appears in [25]. The information on the efficiency values, the power factor, and current for nominal power as well as $75 \%$ and $50 \%$ of this nominal power are supposed to be known. This work starts by supposing that in the magnetic branch resistance the mechanical and additional losses are present. This is, to our understanding, the biggest source of error of this method especially on what is referred to as the additional losses, which are not constant but depend on the load. One of its most important results is the application and validation of the methodology on hundreds of motors as well as the elaboration of per unit characteristics curves of the equivalent circuit parameters as a function of the motor power.

In [26] some universities and research centers from Brazil made a comparison between the main datasheet parameters determination methods, highlighting its robustness and simplicity, and propose a new one that, as they claim, takes the best from the other ones. It is an iterative method that does not consider any specific parameter for the additional losses. In the case of low voltage motors, the only information available is the one provided by the manufacturer's datasheet. In this case, the stator resistance is unknown, and

A new exact equivalent circuit of the medium voltage three-phase induction motor (Laura Collazo Solar) 
the parameters must be calculated from assumptions made of the core, mechanical and additional losses, and by performing an energy balance, this resistance than can be determined as it appears in [22].

Medium-voltage, high-power motors are made to order, and the manufacturer provides more complete information along with the motor, including the value of the stator resistance and the efficiency and power factor for different load states. In some cases, the resistance of the stator is not given, but the no-load current is given. By having more information, it is possible to use an equivalent circuit on which each type of the losses (conventional, variables, and additional) is located on a different resistance. The explanation and validation of this equivalent circuit is the subject of this work. Section 2 presents the equivalent circuit, how losses are considered, and the description of the algorithm to determine the parameters. In section 3 the method is validated by applying it to a case study and in section 4 the conclusions are presented.

\section{RESEARCH METHOD}

\subsection{Proposed equivalent circuit structure and consideration of the losses}

Figure 2 shows the equivalent circuit for medium voltage and high-power motors. The difference between the circuit of Figure 1 is in two aspects. The first is the addition of the resistance $R_{a d}$ where a power equal to the additional losses is considered, the second, that in the resistance $R_{m}$ is considering not only the core losses but also the mechanical losses. This causes the output power of the motor to be considered on the $\mathrm{R}_{2}(1-\mathrm{s}) / \mathrm{s}$ resistance instead of the power converted into complete mechanical form as in the circuit of Figure 1. It is possible, with only the circuit of Figure 2, to carry out a thorough energy efficiency analysis.

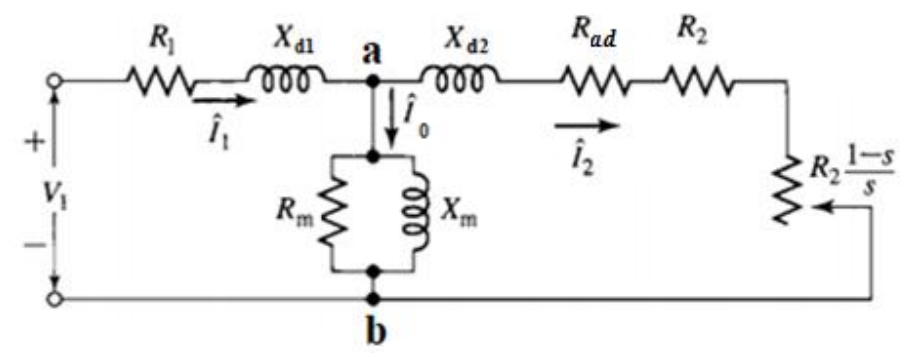

Figure 2. The equivalent circuit for medium voltage and great power motors

The addition of the $\mathrm{R}_{\mathrm{ad}}$ resistance to the rotor's circuit is because the actual additional losses depend on the load, they are not constants as it appears in some texts and articles and is precisely the rotor's current the one that directly depends on the load. There are three types of losses in the motor considered:

- Conventional variable losses. They represent the power turned into heat in the stator and rotor windings and are equal to:

$$
\Delta \mathrm{p}_{\mathrm{vc}}=3 \cdot \mathrm{R}_{1} \cdot \mathrm{I}_{1}^{2}+3 \cdot \mathrm{R}_{2} \cdot \mathrm{I}_{2}^{2}
$$

- Constant losses. Are those that don't depend on the load connected to the motor. These are the core and mechanical losses. Using this circuit, they cannot be separated, and both are considered on the $\mathrm{Rm}$ resistance. It's valued is:

$$
\Delta \mathrm{p}_{\mathrm{cte}}=3 \cdot \frac{\mathrm{E}_{1 \mathrm{n}}^{2}}{\mathrm{R}_{\mathrm{m}}}
$$

- Additional losses. These losses are difficult to evaluate, but they are known to depend on the load connected to the motor and they are calculated as:

$$
\Delta \mathrm{p}_{\mathrm{ad}}=3 \cdot \mathrm{R}_{\mathrm{ad}} \cdot \mathrm{I}_{2}^{2}
$$

\subsection{Parameters determination algorithm}

To apply the proposed algorithm, the following input data are necessary:

- The rated voltage $\mathrm{Vn}$, in $\mathrm{V}$.

- The rated current In, in A. 
- The rated power Pn, in $\mathrm{kW}$.

- The rated speed $\mathrm{nn}$ and the rated synchronous velocity ns, both in rpm.

- The maximum torque, in per unit taking as base quantity the rated torque.

- The efficiency at rated and half rated load.

- The power factor at rated and half rated load.

- The stator resistance R1, in ohms.

The algorithm to detect the parameters follows the next steps:

- The input data described before.

- The determination of the maximum and rated torque through the following expressions:

$$
\begin{aligned}
& \mathrm{T}_{\mathrm{n}}=\frac{\mathrm{P}_{\mathrm{n}} \cdot 1000}{\mathrm{n}_{\mathrm{n}} \cdot \frac{\pi}{30}} \\
& \mathrm{~T}_{\text {max }}=\mathrm{t}_{\text {max }} \cdot \mathrm{T}_{\mathrm{n}}
\end{aligned}
$$

- The determination of the total leakage reactance Xcc and its division in equal parts between the stator and rotor [1]:

$$
\begin{aligned}
& X_{c c}=\frac{V_{n}^{2}}{2 \cdot n_{s} \cdot \frac{\pi}{30} \cdot T_{\max }} \\
& X_{d 1}=X_{d 2}=\frac{X_{c c}}{2}
\end{aligned}
$$

- For half and rated power, the following calculations are performed:

- $\quad$ The input power by dividing the output power by the efficiency for the corresponding load state.

$$
P_{\text {in }}=\frac{P_{\text {out }}}{\eta}
$$

- $\quad$ The stator current applying the following expression:

$$
\mathrm{I}=\frac{\mathrm{P}_{\mathrm{in}}}{\sqrt{3} \cdot V_{\mathrm{n}} \cdot \mathrm{fp}}
$$

- $\quad$ The slip $\mathrm{s}$ where $\mathrm{n}_{\mathrm{S}}$ is the synchronous velocity and $\mathrm{n}$ the rated speed as following:

$$
\mathrm{s}=\frac{\mathrm{n}_{\mathrm{s}}-\mathrm{n}}{\mathrm{n}_{\mathrm{s}}}
$$

- $\quad$ The rotor resistance applying the following expression:

$$
\mathrm{R}_{2}=\frac{\mathrm{s} \cdot \mathrm{P}_{\mathrm{sal}} \cdot 1000}{3 \cdot(1-\mathrm{s}) \cdot(\mathrm{I} \cdot \mathrm{fp})^{2}}
$$

- $\quad$ The induced emf (electromotive force) through the following complex expressions:

$$
\begin{aligned}
& \overline{\mathrm{E}}_{1}=\overline{\mathrm{V}}_{1}-\mathrm{j} \cdot \overline{\mathrm{I}} \cdot\left(\mathrm{R}_{1}+\mathrm{j} \cdot \mathrm{X}_{\mathrm{d} 1}\right) \\
& \overline{\mathrm{I}}=\mathrm{I} \cdot \mathrm{fp}-\mathrm{j} \cdot \mathrm{I} \cdot \sqrt{1-\mathrm{fp}^{2}}
\end{aligned}
$$

- The no-load current component $90^{\circ}$ from the induced emf $I_{\text {or. }}$

- $\quad$ The magnetizing reactance through the expression:

$$
\mathrm{X}_{\mathrm{m}}=\frac{\mathrm{E}_{1}}{\mathrm{I}_{\mathrm{or}}}
$$

- A new variable equal to three times the square of the rotor's current:

$$
\operatorname{corr} 2=3 \cdot I_{2}^{2}
$$


- $\quad$ The sum of the losses as the difference between the input and output power:

$\sum$ losses $=\mathrm{P}_{\text {in }}-\mathrm{P}_{\text {out }}$

- A new value named $p_{\text {acad }}$ which is the sum of the constant and additional losses:

$$
\mathrm{p}_{\text {acad }}=\sum \text { losses }-\left(3 \cdot \mathrm{I}_{1}^{2} \cdot \mathrm{R}_{1}+3 \cdot \mathrm{I}_{2}^{2} \cdot \mathrm{R}_{2}\right)
$$

- The functional relation between pacad and the variable corr2 $=3 . \mathrm{I} 22$ is a straight line with an intercept at the loss's axis. This intercept is the constant losses and the slope of the line is the resistance of the additional losses as it is shown in Figure 3.

To determine the intercept and the slope the Newton interpolation method is used.

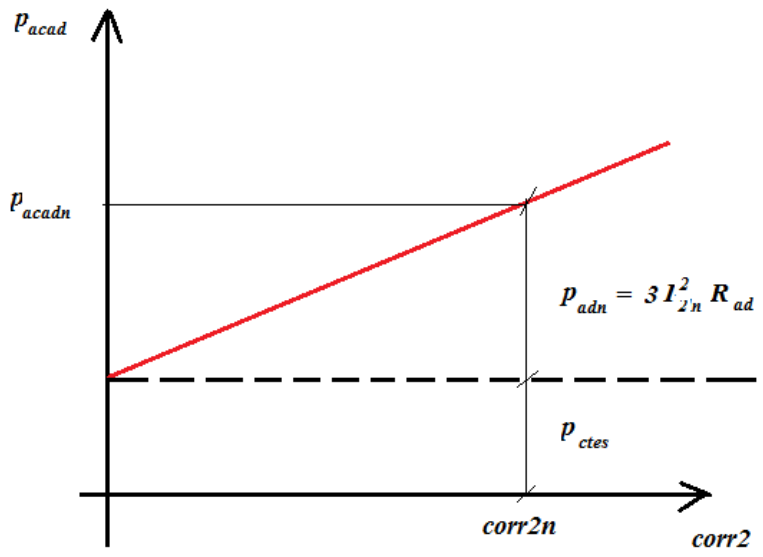

Figure 3. Constant and additional losses

\section{RESULTS AND DISCUSSION}

\subsection{Case study}

The feeding pump motor of the Máximo Gómez Power Plant at Mariel, Cuba is chosen as a case study. The motor's data appears in Table 1. The algorithm explained in the previous epigraph was carried and the results that appear in Table 2 were obtained.

Table 1. Data of the case study motor

Rated power, in $\mathrm{kW} \quad 2500$

Rated voltage, in V 6000

Rated speed, in rpm 3580

Synchronous speed, in rpm $\quad 3600$

Efficiency at 50\% load, in \% $\quad 96.4$

Efficiency at $100 \%$ load, in \% 97

Power factor at $50 \%$ load, in \% $\quad 0.80$

Power factor at $100 \%$ load, in \% $\quad 0.88$

Stator resistance, in ohms $\quad 0.0472$

Maximum torque, in p.u. $\quad 2.5$

Table 2. Parameters of the case study motors

\begin{tabular}{cc}
\hline Stator's resistance $\mathrm{R}_{1}$, in ohms & 0.049 \\
Stator's leakage reactance $\mathrm{X}_{\mathrm{d} 1}$, in ohms & 1.432 \\
Constant losses resistance $\mathrm{R}_{\mathrm{m}}$, in ohms & 925.05 \\
Magnetizing resistance $\mathrm{X}_{\mathrm{m}}$, in ohms & 40.82 \\
Rotor's leakage reactance $\mathrm{X}_{\mathrm{d} 2}$, in ohms & 1.432 \\
Rotor's resistance $\mathrm{R}_{2}$, in ohms & 0.0749 \\
Additional losses resistance $\mathrm{R}_{\mathrm{ad}}$, in ohms & 0.1041 \\
\hline
\end{tabular}




\subsection{Validation of the parameter's calculation methodology}

The validation of this methodology is done in two different ways.

- The power factor and efficiency are determined by $25 \%, 75 \%$, and $125 \%$ of the rated load and is compared to the value given by the manufacturer.

- By solving the equivalent circuit for the values of currents measured experimentally at the power plant, the active and reactive power values are determined and are compared with the experimental values. The results obtained are shown in Table 3.

Table 3. Validation using the first path

\begin{tabular}{cccc}
\hline Conditions & Manufacturer value & Calculated value & Error (\%) \\
\hline 25\% efficiency & 94 & 94 & 0 \\
$75 \%$ efficiency & 96.9 & 96.8 & -0.103 \\
125\% efficiency & 96.8 & 96.6 & -0.206 \\
$25 \%$ power factor & 0.620 & 0.601 & 3.06 \\
$75 \%$ power factor & 0.860 & 0.857 & 0.34 \\
$125 \%$ power factor & 0.880 & 0.875 & 0.56 \\
\hline
\end{tabular}

For the validation of the method using the second path, the active and reactive power input data are calculated from the measured current and voltage values at the power plant, utilizing the proposed equivalent circuit. Later these values are compared with the experimental values. The results obtained are presented in Table 4.

In this Table VF is the phase voltage, $\mathrm{F}$ the frequency, I FASE the phase current, $\mathrm{P}$ REAL the measured real power, P CAL the calculated power, \% E_P the input power error, Q REAL the measured reactive power, Q CAL the calculated reactive power and \% E_Q the input reactive power error. It can be appreciated that in every case these errors are smaller than $10 \%$, being the most frequent the smaller than $5 \%$.

Table 4. Validation by the second path

\begin{tabular}{lllllllllll}
\hline Date & Time & VF & F & IFASE & P REAL & P CAL & \% E_P & Q REAL & Q CAL & \% E_Q \\
\hline $20-11$ & $11: 00$ & 3510 & 59.9 & 221 & 2047 & 1995 & 2.5 & 1140 & 1195 & -4.8 \\
$20-11$ & $2: 00$ & 3510 & 60.1 & 216.5 & 2091 & 1950 & 2.8 & 1071 & 1083 \\
$21-11$ & $11: 00$ & 3490 & 60 & 214 & 1972 & 1914 & 2.9 & 1064 & 1165 \\
$23-11$ & $18: 00$ & 3520 & 60.1 & 236 & 2218 & 2153 & 2.9 & 1180 & 1255 \\
$28-11$ & $18: 00$ & 3510 & 59.6 & 231 & 2140.5 & 2085 & 2.6 & 1100 & 1155 & -6.5 \\
$30-11$ & $8: 00$ & 3550 & 60 & 229.6 & 2151 & 2086 & 3.02 & 1140 & 1161 & -1.8 \\
\hline
\end{tabular}

\section{CONCLUSION}

The elaboration of an equivalent circuit and the method for the calculation of the parameters of medium voltage and high power motors based on the fact that, for this kind of motors, generally there is bigger information supplied by the manufacturer, especially the knowledge of the stator resistance, have been achieved. This method has the following advantages: (a) it doesn't need suppositions related to the core, mechanical or additional losses; (b) with the inclusion of the Rad resistance, additional losses as variable losses with the load can be taken into consideration; (c) by putting together, the mechanical and core losses in the resistance $\mathrm{Rm}$, the calculation of the constant losses without making an appreciable mistake is made easier; (d) a power balance considering only the equivalent circuit balance can be carried out because: (i) the stator copper losses are considered at resistance R1; (ii) the constant losses: core and mechanics are considered at the resistance Rm; (iii) the rotor copper losses are considered at resistance R2; (iv) the additional losses are considered at resistance Rad; (v) the mechanical power output in the motor's shaft is the power that is considered at the R2 (1-s)/s resistance. In the conventional equivalent circuit, all the power transformed into the mechanical form including the mechanical and additional losses dissipates on this resistance.

\section{REFERENCES}

[1] P. R. Viego, V. Sousa, J. R. Gómez, and E. C. Quispe, "Direct-on-line-start permanent-magnet-assisted synchronous reluctance motors with ferrite magnets for driving constant loads," International Journal of Electrical and Computer Engineering (IJECE), vol. 10, no. 1, pp. 651-659, 2020.

[2] J. R. Gómez, V. Sousa, M. S. Quintana, P. R. Viego, H. Hernández, and E. C. Quispe, "Flow regulation at constant head in feedwater pumps in a sugar industry," International Journal of Electrical and Computer Engineering (IJECE), vol. 9, no. 2, pp. 732-741, 2019. 
[3] A. E. Fitzgerald, C. Kingsley, and S. D. Umans, "Electric machinery. Ch 01: Magnetic circuits and magnetic materials.," Electric Machinery, McGraw-Hill, pp. 1-56, 2003.

[4] M. Vilaragut, Á. Costa, and A. Garcia, "Métodos para la determinación de la eficiencia energética en los motores de inducción trifásicos," Rev. Cient. las energias Renov., 2004.

[5] Á. Costa and M. Vilaragut, "Determinación del comportamiento energético del motor de inducción a partir de sus datos de catálogo y la lectura de las corrientes del estator," III Taller Caribeño de Energía y Medio Ambiente., 2004.

[6] T. A. Lipo, "A. Introduction to AC machine design," John Wiley \& Sons, 2017.

[7] D. Dolinar, G. Stumberger, R. Belmans, and E. Freeman, "Determination of the induction motor model parameters using finite elements," International Conference on Electrical Machines, pp. 153-158, 1996.

[8] Heng Phalla Sambath, "Method for determining losses and efficiency of three-phase cage induction motors," IEE Half Day Colloquium Testing of Electrical Machines, 2002.

[9] IEEE, "IEEE Standard Test Procedure for Polyphase Induction Motors and Generators," IEEE Std 112-2017 (Revision of IEEE Std 112-2004), pp. 1-115, 2018.

[10] IEC, "IEC 60034-28. Rotating electrical machines-Part 28: Test methods for determining quantities of equivalent circuit diagrams for three-phase low-voltage cage induction motors," 2012.

[11] L. A. D. S. Ribeiro, C. B. Jacobina, and A. M. N. Lima, "Parameter estimation of induction machines under sinusoidal PWM excitation," IEEE Trans. Energy Convers., 1999.

[12] WEG, "General purpose motor catalog," 2017.

[13] SIEMENS, "General purpose motor catalog," 2017.

[14] ABB, "General purpose motor catalog," 2018.

[15] R. Natarajan and V. K. Misra, "Parameter estimation of induction motors using a spreadsheet program on a personal computer," Electr. Power Syst. Res., vol. 16, no. 2, pp. 157-164. 1989.

[16] S. . Umans, "Fitzgerald and Kingsley's Electric machinery," McGraw-Hill Higher Education, vol. 319, no. 4. 2014.

[17] S. Ansuj, F. Shokooh, and R. Schinzinger, "Parameter Estimation for Induction Machines Based on Sensitivity Analysis," IEEE Trans. Ind. Appl., vol. 25, no. 6, pp. 1035-1040, 1989.

[18] M. H. Haque, "Estimation of three-phase induction motor parameters," Electr. Power Syst. Res., vol. 26, no. 3, pp. 187-193,1993.

[19] J. Pedra, "On the determination of induction motor parameters from manufacturer data for electromagnetic transient programs," IEEE Trans. Power Syst., vol. 23, no. 4, pp. 1709-1718, 2008.

[20] J. Pedra, "Estimation of typical squirrel-cage induction motor parameters for dynamic performance simulation," IEE Proc. Gener. Transm. Distrib., vol. 153, no. 2, pp. 137-146, 2006.

[21] J. Pedra and F. Córcoles, "Estimation of induction motor double-cage model parameters from manufacturer data," IEEE Trans. Energy Convers., vol. 19, no. 2, pp. 310-317, 2004.

[22] X. M. L.-F. Angel Costa Montiel, Gloria Ciembulea, Neculai Galan, "Cálculo de los parámetros del motor de inducción a partir de datos de catálogo," Energía y Comput., vol. 12, no. 2, pp. 32-38, 2004.

[23] J. Pedra, I. Candela, and A. Barrera, "Saturation model for squirrel-cage induction motors," Electr. Power Syst. Res., vol. 79, no. 7, pp. 1054-1061, 2009.

[24] M. Torrent, "Estimation of equivalent circuits for induction motors in steady state including mechanical and stray load losses," Eur. Trans. Electr. Power, vol. 22, no. 7, pp. 989-1015, 2012.

[25] J. M. C. Guimaraes, J. V. Bernardes, A. E. Hermeto, and E. D. C. Bortoni, "Parameter determination of asynchronous machines from manufacturer data sheet," IEEE Trans. Energy Convers., vol. 29, no. 3, pp. 689-697, 2014.

[26] C. A. C. Wengerkievicz et al., "Estimation of three-phase induction motor equivalent circuit parameters from manufacturer catalog data," J. Microwaves, Optoelectron. Electromagn. Appl., vol. 16, no. 1, pp. 90-107, 2017.

\section{BIOGRAPHIES OF AUTHORS}

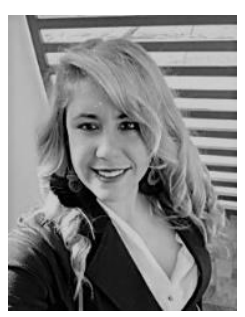

Laura Collazo Solar was born in Havana, Cuba, on November 30, 1989. Received a B.Sc. in Electrical Engineering from Universidad Tecnológica de la Habana José Antonio Echeverría, Cuba in 2013. M.Sc. in Electrical Engineering from Universidad Tecnológica de la Habana José Antonio Echeverría, Cuba in 2020. She has published papers in induction motors parameters identification and energy efficiency. Her area of interest includes electric machines and drives and energy efficiency.

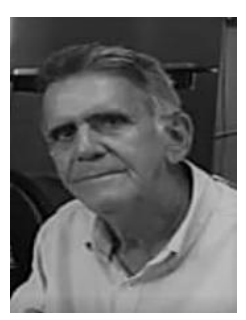

Angel A. Costa Montiel was born in Havana, Cuba, on March 21, 1944. Received a B.Sc. in Electrical Engineering from University of Havana, Cuba in 1968. PhD. in Technical Sciences (Electrical Engineering) from Universidad Tecnológica de la Habana José Antonio Echeverría, Cuba, in 1987. He has published papers in high impact journals indexed in Scopus in induction motors parameters identification, vector control of electric motors and artificial intelligence application to control of electric machines and drives. His area of interest are simulation and control of electric machines and drives and energy efficiency. 

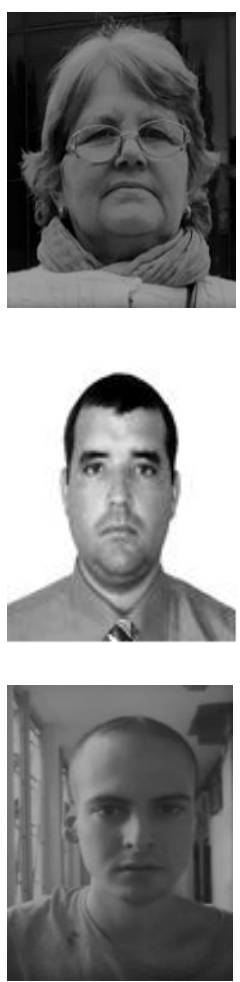

Miriam Vilaragut Llanes was born in Cienfuegos, Cuba, on April 13, 1959. Received a B.Sc. in Electrical Engineering from Universidad Tecnológica de la Habana José Antonio Echeverría, Cuba in 1982. M.Sc. in Electrical Engineering from Universidad Tecnológica de la Habana José Antonio Echeverría, Cuba in 1982. PhD. in Technical Sciences (Electrical Engineering) from Universidad Tecnológica de la Habana José Antonio Echeverría, Cuba, in 2002. She has published articles on electric drive, renewable energy sources and capacity building in high impact journals indexed in Scielo, Scopus and Wos. Her area of interest includes electric drives, renewable energy sources, and electric power system.

Vladimir Sousa Santos was born in Cienfuegos, Cuba, on November 21, 1980. Received a B.Sc. in Electrical Engineering from the Universidad Central de Las Villas, Cuba in 2004. M.Sc. in Energy Efficiency from Universidad Cienfuegos, Cuba in 2004. PhD. in Electrical Engineering from Universidad Central de Las Villas, Cuba, in 2014. He has published articles on induction motors, energy quality and energy efficiency in high impact journals indexed in Scopus and Wos. His area of interest includes electric machines, power quality, and energy efficiency.

Abel Curbelo Colina was born in Havana, Cuba, on November 1, 1999. Received a B.Sc. in Electrical Engineering from Universidad Tecnológica de la Habana José Antonio Echeverría, Cuba in 2018. His area of interest includes electric machines, power quality, and energy efficiency. 